\title{
Hormones and Cancer is Alive and Well at ICE/ENDO 2014
}

\author{
Carol A. Lange
}

Published online: 26 April 2014

(C) Springer Science+Business Media New York 2014

This June 21-24 kicks off the joint meetings of the 16th International Congress of Endocrinology (ICE) and The Endocrine Society's (ES) 96th Annual Meeting \& Expo. Of note, this joint meeting held in Chicago (McCormick Place Convention Center) will be the world's largest gathering of scientists and endocrinologists working in the field of hormone research, including those focused on the intersection of hormones and cancer.

Launched in 2009, Hormones and Cancer is a relatively new addition to The Endocrine Society's list of esteemed publications (http://press.endocrine.org/). However, the topic has long been integrated as a mainstay of annual ES programming. The 2014 ICE/ENDO program includes numerous symposia that touch on the theme of hormones and cancer, including the emerging role of extranuclear signaling actions of steroid hormones and their receptors (featured herein for estrogen receptors in a new review article from Dr. Ellis R. Levin (UC Irvine)) entitled "Translating ExtraNuclear Steroid Receptor Signaling to Clinical Medicine". Steroid hormone receptors are now well known to traffic to the plasma membrane, where they modulate signal transduction important for cellular homeostasis and gene regulation. Most recently, their role in mitochondrial function and metabolism is being investigated. These functions clearly impact cancer and as such, are potential targets for therapeutic intervention.

Indeed, Hormones and Cancer remains the only ES journal that includes basic, translational, and clinical contents (see our scope statement at http://www.springer.com/medicine/

C. A. Lange $(\bowtie)$

Departments of Medicine and Pharmacology, University of

Minnesota, Minneapolis, MN 55455, USA

e-mail: lange047@umn.edu

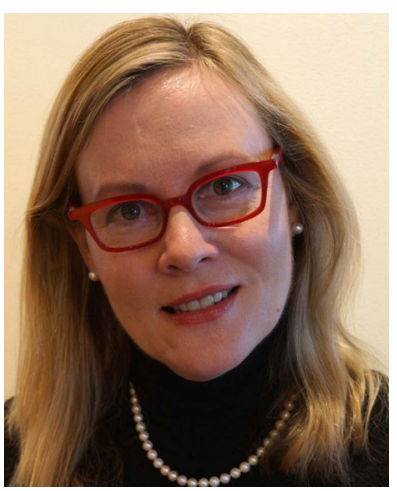

Carol A. Lange, PhD

oncology/journal/12672). Consistent with our scope, upcoming ICE/ENDO 2014 programming of interest to readers of Hormones and Cancer may include the following:

Plenary Lecture:

"Environmental Endocrine Disruptors and the Developing Brain"

Dr. Andrea Gore (UT Austin) Tuesday June 24th 8:50 AM-9:15 AM

Symposia:

"Prostate Cancer Biomarkers, Stem Cells \& Therapy" Sunday, June 22, 2014: 5:00 PM-6:30 PM

"Novel Biomarkers \& Targets of Therapy for Endocrine Resistant Breast \& Prostate Cancer" Monday, June 23, 2014: 5:00 PM-6:30 PM

"Gasping for Air: Hypoxia \& Endocrine Cancers" Tuesday, June 24, 2014: 11:15 AM-12:45 PM 
"AMPK \& Endocrine-Related Cancers"

Saturday, June 21, 2014: 5:00 PM-6:30 PM

"Health Disparities in Endocrine Cancers"

Saturday, June 21, 2014: 5:00 PM-6:30 PM

"MicroRNAs \& Hormones in Aging \& Disease"

Tuesday, June 24, 2014: 11:15 AM-12:45 PM

"Bone, Marrow \& Fat Connections"

Sunday, June 22, 2014: 9:30 AM-11:00 AM

"Shifting Focus in Thyroid Hormone Regulation of Metabolism"

Sunday, June 22, 2014: 5:00 PM-6:30 PM

"The Genome on Steroids"

Saturday, June 21, 2014: 9:30 AM-11:00 AM

"The year in Vitamin D"

Saturday, June 21, 2014: 5:00 PM-6:30 PM

"Navigating Biomedical Big Data"

Tuesday, June 24, 2014: 11:15 AM-12:45 PM
Additionally, exciting new programming at ICE/ENDO 2014 includes the Translational Research Workshop: "T1-From Basic Science to Human Clinical Insights" held in the afternoon of Friday June 20th. Programming includes focus on methods for overcoming the challenges and obstacles to translation of our best basic science into clinical application as well as advice on academic team building and ways to establish new partnerships for effective and timely translation, including how to develop translational strategies for the creation of competitive funding applications.

On behalf of The Editorial Board of Hormones and Cancer, I wish you a productive and exciting ICE/ENDO 2014. As always, thank you for your contributions to our vibrant world of Endocrinology!

Carol A. Lange, $\mathrm{PhD}$

Editor-in-Chief

Hormones and Cancer 